Article

\title{
Structure-Property Studies on a New Family of Halogen Free Flame Retardants Based on Sulfenamide and Related Structures
}

\author{
Teija Tirri, Melanie Aubert, Weronika Pawelec, Anton Holappa and Carl-Eric Wilén * \\ Faculty of Science and Engineering, Chemical Engineering, Polymer Technology and Center for \\ Functional Materials, Åbo Akademi University, Biskopsgatan 8, Abo 20500, Finland; Teija.tirri@abo.fi (T.T.); \\ maubert@abo.fi (M.A.); WPawelec@uclan.ac.uk (W.P.); anton.holappa@gmail.com (A.H.) \\ * Correspondence: cwilen@abo.fi; Tel.: +358-2-215-4308
}

Academic Editors: Baljinder Kandola, Abderrahim Boudenne and Paul Kiekens Received: 20 July 2016; Accepted: 29 September 2016; Published: 14 October 2016

\begin{abstract}
A wide variety of molecules containing S-N or S-N-S cores were synthesized, and their flame retardant properties in polypropylene (PP), low density polyethylene (LDPE) and polystyrene (PS) were investigated. In addition, polymers or oligomers bearing the sulfenamide functionality (SN) were also synthesized. It was shown that this radical generator family based on sulfenamides is very versatile in terms of structural modifications, and the thermal decomposition range can be easily adjusted by changing the $R$ groups attached to the core. The thermal stabilities of the different sulfenamides were examined by thermogravimetric analysis (TGA). Radicals generated by the homolytic cleavage of the S-N or S-N-S bonds at an elevated temperature can effectively interact with the intermediate products of polymer thermolysis and provide excellent flame retardant properties. The choice of most suitable SN-structure varies depending on the polymer type. For polypropylene DIN 4102-1 B2 and UL94 VTM-2 classifications were achieved with only 0.5 to $1 \mathrm{wt} \%$ of sulfenamide, and, in some cases, no flaming dripping was observed. Also for LDPE thin films, sulfenamides offered the DIN 4102-1 B2 rating at low dosage. In the case of polystyrene, the very stringent UL94 V-0 classification was even achieved at a loading of $5 \mathrm{wt} \%$ of sulfenamide.
\end{abstract}

Keywords: sulfenamide; radical generator; halogen free; flame retardant; polypropylene; polystyrene

\section{Introduction}

In response to the urgent need to develop new high-performance and halogen-free fire resistant materials with low environmental impact [1], different alternative flame retardant (FR) systems have been introduced. In many applications, traditional inorganic, non-halogenated flame retardants such as ammonium polyphosphate (APP) and aluminum or magnesium hydroxides (ATH, MDH) are widely used, but there is still a need to find more effective solutions. A vast majority of the proposed solutions are based on different reactive or additive organophosphorus or nitrogen containing additives that can act in gas phase and/or in condensed phase [2-5]. In addition, various families of radical generators have been prepared and their viability in a series of polymer applications has been recently demonstrated [6-13].

Most plastic materials require specific FRs for optimal fire safety; furthermore, FR materials must often fulfill very application-specific fire safety demands in order to pass various fire safety standards established for plastic components. Coating, construction, textiles, electric/electronic (E\&E) and transportation industries have additionally various requirements on the additives used in their polymer materials; temperature stability, being solid or liquid, viscosity, polarity and miscibility are only a few properties which need to be matched between a suitable FR, the polymer, the production 
process and the product. Hence, the optimal flame retardant solution and the obtained level of flame retardancy depend on the polymer type and application. In this respect, flame retardants that can be compounded at temperatures $\geq 230{ }^{\circ} \mathrm{C}$, have high hydrolytic stability, and do not require high loadings (below $10 \%$ by weight) in order to achieve compliance with UL94 V-0 would be highly desired. In addition, they should have a reasonable price compared to the halogen-containing flame retardant systems.

Along with phosphorus, nitrogen and silicon, sulfur is one of the known flame retardant elements, but compared to the others, sulfur containing compounds have been much less extensively studied as flame retardants. However, disulfide based radical generators alone or in combination with phosphorus compounds have shown good flame retardant effects both in polypropylene (PP) and polystyrene (PS) [12,14]. Replacing $\mathrm{P}=\mathrm{O}$ bonds with $\mathrm{P}=\mathrm{S}$ in 9,10-dihydro-oxa-10-phosphaphenanthrene-10-oxide (DOPO) enhanced gas phase FR activity in epoxy matrix [15]. An approach to combine $\mathrm{P}, \mathrm{N}$ and $\mathrm{S}$ to an effective char forming FR for thermoplastic polyurethane has also been reported recently [16].

We have discovered that sulfenamides, a specific group of compounds containing a bond of divalent sulfur and trivalent nitrogen, which by homolytical cleavage generate aminyl and thiyl radicals, provide excellent flame retarding properties to polymer substrates [17]. Sulfenamides (SN) contain two reactive centers, and can be attacked both by nucleophiles on $\mathrm{S}$ and by electrophiles on N. Formation of sulfenamides was reported already in 1911 by Zincke [18]. Since then, sulfenamides and related structures have been extensively studied as intermediates in organic and peptide synthesis and used in various applications including pharmaceuticals, fungicides and rubber vulcanization [19-21]. One of the very attractive features of sulfenamide compounds is their versatility; by changing the $R$ groups attached to $S$ and $N$, very different kinds of chemical and physical properties can be obtained. Hydrophobicity, thermal properties and stability in different chemical environments can be tailored to fit the application-specific requirements. Both small molecules and polymers can be easily synthesized. The synthesis of first polysulfenamides using secondary diamines and dithiosuccinimid sulfenyl transfer agent was described in 2011 [22-24]. These polymers are based on aliphatic and cycloaliphatic constituents, and they readily degrade in water. In vivo and in vitro toxicological studies of the fabricated polysulfenamide microparticles showed little or no adverse effects, and were therefore proposed to be a new class of biodegradable polymers for drug delivery.

Eichhorn has shown already in the 1960s that certain radical generators such as peroxides, benzothiazole, sulfenamides, disulfides and bibenzyl compounds can be used as synergists with brominated flame retardants in vinyl aromatic polymers $[25,26]$. Eichhorn reported that radical precursors including sulfenamides trigger the decomposition of halogenated FRs, whereby halogen radicals are rapidly liberated which effectively interrupts the combustion process. Thus, according to Eichhorn, without the addition of halogenated flame retardant, self-extinguishing of the flame will not occur if only a free radical generator per se is employed. To the best of our knowledge, the use of sulfenamides and related structures as independent fire protection agents is not found in prior literature.

The excellent flame retarding action of various sulfenamide compounds on polypropylene, low density polyethylene and polystyrene when exposed to small heat source is reported herein. The novel sulfenamide flame retardants have been divided into six groups based on their structure, as shown in Figure 1.

Even polymeric structures with sulfenamides attached as pendant groups are presented. In general, oligomeric or polymeric plastic additives are sometimes preferred, especially in pipe and textile applications, since polymeric additives are less prone to physical loss compared to low molecular weight ditto, when in contact with aggressive service environments such as organic solvents and/or detergents. 


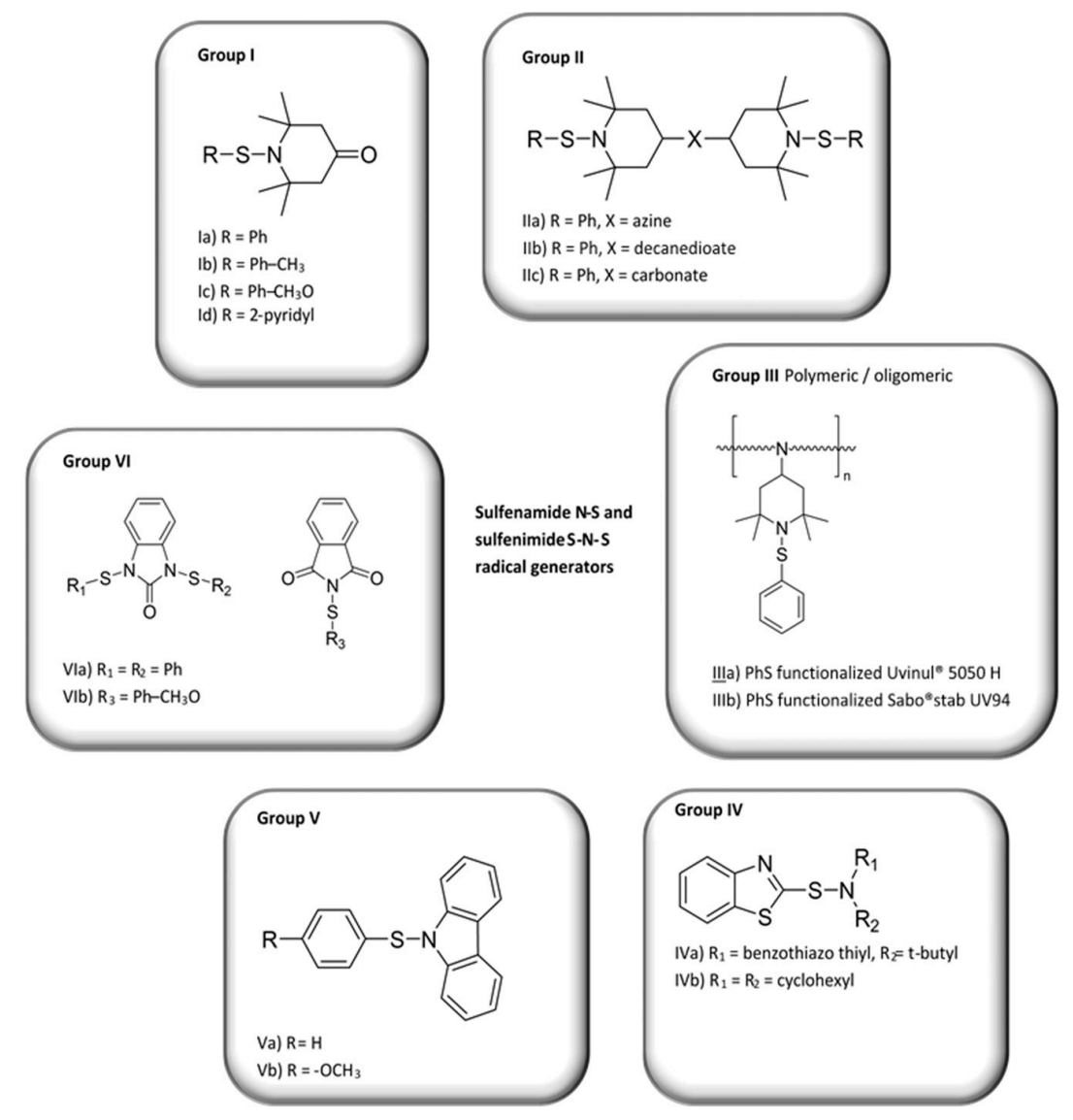

Figure 1. Grouping of sulfenamides.

\section{Experimental Section}

Synthesis and characterization of the SN compounds Ia-VIb are described in a recently filed patent [17]. All chemicals used were of reagent grade and purchased from Aldrich (Helsinki, Finland), ABCR (KArlsruhe, Germany) or Wako Chemicals GmbH (Neuss, Germany), except for the commercial samples obtained from BTC Europe (Uvinul ${ }^{\circledR} 5050$ H, Irganox ${ }^{\circledR}$ B 225, Rhein, Germany), Songwon Industrial Co. (Sabo ${ }^{\circledR}$ stab UV 94, Ulsan, Korea) and Flexsys (Santocure TBSI, now part of Eastman, Capelle aan den IJssel, Holland). The Santocure TBSI (Compound IVa) was purified by trituration with isopropanol before use. Irganox ${ }^{\circledR}$ B 225 is a processing and long-term thermal stabilizer, a blend of 50\% tris(2,4-ditert-butylphenyl) phosphite and 50\% pentaerythritol tetrakis[3-[3,5-di-tert-butyl-4-hydroxyphenyl]propionate].

${ }^{1} \mathrm{H}$ and ${ }^{13} \mathrm{C}$ NMR spectra were recorded on a Bruker Avance $600\left({ }^{1} \mathrm{H} 600.1 \mathrm{MHz},{ }^{13} \mathrm{C} 150.9 \mathrm{MHz}\right)$ (Billerica, MA, USA). Thermogravimetric analyses (TGA) were performed using an SDT Q600 apparatus from TA Instruments (New Castle, DE, USA) under $\mathrm{N}_{2}$ atmosphere at a heating rate of $10^{\circ} \mathrm{C} / \mathrm{min}$.

Flame retardants were melt mixed in polypropylene (PP, MOPLEN HP500N from LyondellBasell, Rotterdam, Holland, melt flow rate (MFR) $\left.12 \mathrm{~g} / 10 \mathrm{~min}\left(230^{\circ} \mathrm{C} / 2.16 \mathrm{~kg}\right)\right)$ and low density polyethylene (LDPE, Borealis Polymers CA7230, Kulloo, Finland, MFR $4.5 \mathrm{~g} / 10 \mathrm{~min}\left(190{ }^{\circ} \mathrm{C} / 2.16 \mathrm{~kg}\right)$ ) in a Haake Rheocord melt blender (Waltham, MA, USA) (60 rpm). Polypropylene was melted first for $1 \mathrm{~min}$ at $210^{\circ} \mathrm{C}$, where after processing aids Ca-stearate (Baerlocher, Unterschleißheim, Germany, $0.05 \mathrm{wt} \%)$ and Irganox ${ }^{\circledR}$ B $225(0.3 \mathrm{wt} \%)$ were added. After one minute, flame retardant was added and the mixing was continued for five minutes. LDPE was processed similarly at $190{ }^{\circ} \mathrm{C}$ but without processing aids. Test films $(200 \mu \mathrm{m}$ and $1 \mathrm{~mm})$ were compression molded in a hot press at $210^{\circ} \mathrm{C}$ for PP and at $135{ }^{\circ} \mathrm{C}$ for PE. Polystyrene (GPPS 25SPI, LG Chemicals,Frankfurt, Germany) formulation was 
compounded by twin screw extrusion with die temperature set at $200^{\circ} \mathrm{C}$, followed by injection molding at $200^{\circ} \mathrm{C}$ into $1.6 \mathrm{~mm}$ thick strips $\left(127 \times 12.7 \mathrm{~mm}^{2}\right)$ for UL 94 tests. All samples were conditioned three days prior to testing $\left(23^{\circ} \mathrm{C}, 50 \% \mathrm{RH}\right)$.

The flame retardant effect was investigated in accordance with a modified DIN 4102-1 B2. The flame application time was $15 \mathrm{~s}$ with a $40 \mathrm{~mm}$ flame height and edge ignition. Polystyrene samples were tested according to UL94 standard [27].

\section{Results and Discussion}

In the course of this study, a series of radical precursors based on sulfenamide derivatives were prepared in order to explore their utility as novel flame retardants for polyolefins. The prepared sulfenamide compounds were divided into six groups based on their chemical structures and their thermal stabilities were examined by TGA studies.

\subsection{Synthesis of Sulfenamides}

The general synthetic pathways for the preparation of sulfenamides have been reviewed in the literature $[19,28-33]$. The most common synthetic approaches to sulfenamides are depicted in Figure 2.

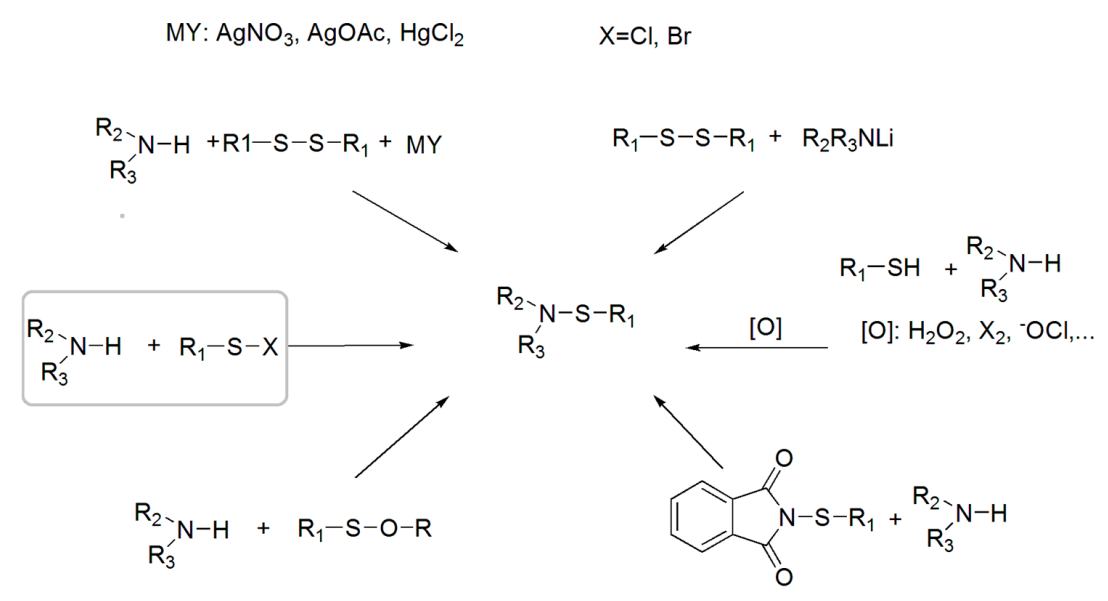

Figure 2. General synthetic methods developed for generating sulfenamide derivatives.

The reaction of alkylthionyl chloride with an amine as highlighted in Figure 2 was used as a facile synthetic route for the generation of the targeted sulfenamide derivatives. Either excess of the same amine or triethyl amine was used to scavenge hydrogen chloride that was released during the reaction. The alkylsulfenyl chlorides were prepared from the corresponding disulfides or thiols by chlorination with $\mathrm{Cl}_{2}$ or $\mathrm{SO}_{2} \mathrm{Cl}_{2}$ in dry aprotic solvents. As an example, synthesis of the compound IIc is described here (Scheme 1).

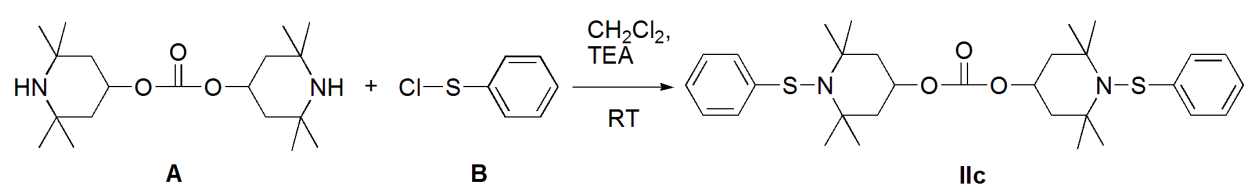

Scheme 1. Synthesis of bis(2,2,6,6-tetramethyl-1-(phenylthio)piperidin-4-yl) carbonate.

\subsubsection{Bis(2,2,6,6-tetramethylpiperidin-4-yl) Carbonate (Diamine A)}

The diamine A was prepared by transesterification reaction between diphenyl carbonate and 2,2,6,6-tetramethylpiperidinol. Under argon atmosphere, 2,2,6,6-tetramethyl-4-piperidinol $(10 \mathrm{~g}, 64 \mathrm{mmol})$, diphenyl carbonate $(6.8 \mathrm{~g}, 32 \mathrm{mmol})$ and potassium carbonate $(0.58 \mathrm{~g}, 4 \mathrm{mmol})$ were 
dispersed in mineral spirits $(65 \mathrm{~mL})$. The reaction mixture was refluxed at $180^{\circ} \mathrm{C}$ for $8 \mathrm{~h}$. The mixture was left to cool down to $50^{\circ} \mathrm{C}$ and washed with warm water $(3 \times 60 \mathrm{~mL})$. White precipitate appeared upon cooling down to RT, which was filtrated off and dried under reduced pressure at $90{ }^{\circ} \mathrm{C}$ to remove residues of water and phenol. Pure product was obtained in $51 \%$ yield, $5.5 \mathrm{~g}$.

${ }^{1} \mathrm{H}$ NMR $\left(\mathrm{CDCl}_{3}\right): 5.04(\mathrm{~m}, \mathrm{CH}, 2 \mathrm{H}), 2.04\left(\mathrm{~d}, \mathrm{CH}_{2}, 2 \mathrm{H}\right), 2.02\left(\mathrm{~d}, \mathrm{CH}_{2}, 2 \mathrm{H}\right), 1.25\left(\mathrm{~s}, \mathrm{CH}_{3}, 12 \mathrm{H}\right)$, $1.20(\mathrm{~m}, 4 \mathrm{H}), 1.17\left(\mathrm{~s}, \mathrm{CH}_{3}, 12 \mathrm{H}\right)$.

${ }^{13} \mathrm{C}$ NMR $\left(\mathrm{CDCl}_{3}\right): 154.28,72.70,51.76,44.05,35.01,28.81$.

\subsubsection{Benzenesulfenyl Chloride (B)}

A three-necked reaction flask equipped with a reflux condenser fitted with an acid gas receiver (15\% $\mathrm{NaOH}$ solution) was charged with phenyl disulfide $(10 \mathrm{~g}, 46 \mathrm{mmol})$ and dry $\mathrm{CH}_{2} \mathrm{Cl}_{2}(100 \mathrm{~mL})$. The solution was cooled down to $-18{ }^{\circ} \mathrm{C}$ and $\mathrm{Cl}_{2}$ gas was passed in over $20 \mathrm{~min}$. The solution got a strong orange-red color. The cooling bath was allowed to warm up to $-5{ }^{\circ} \mathrm{C}$, and then the flask was removed from the bath and the solution was stirred gently for $30 \mathrm{~min}$ under argon flow. The complete conversion of the disulfide into phenylsulfenyl chloride was confirmed by ${ }^{1} \mathrm{H} N \mathrm{NR}$ without solvent removal.

${ }^{1} \mathrm{H}$ NMR $\left(10 \% \mathrm{CDCl}_{3}\right): \delta 7.39-7.45(\mathrm{~m}, 3 \mathrm{H}), 7.65-7.7(\mathrm{~m}, 2 \mathrm{H})$.

\subsubsection{Bis(2,2,6,6-tetramethyl-1-(phenylthio)piperidin-4-yl) Carbonate (Structure IIc)}

Diamine A $(0.5 \mathrm{~g}, 1.5 \mathrm{mmol})$ was dissolved in dry dichloromethane $(5 \mathrm{~mL})$ in an argon atmosphere, and triethylamine $(0.52 \mathrm{~mL}, 3.6 \mathrm{mmol})$ was added. Then, benzenesulfenyl chloride in $\mathrm{CH}_{2} \mathrm{Cl}_{2}(4.07 \mathrm{~mL}$, $3.7 \mathrm{mmol}$ ) was added dropwise. After complete addition, the reaction mixture was stirred at room temperature for $2 \mathrm{~h}$. The organic phase was washed with water $(3 \times 10 \mathrm{~mL})$, dried over $\mathrm{Na}_{2} \mathrm{SO}_{4}$ and evaporated. The product was recrystallized twice from diethyl ether and the title compound was obtained in $84 \%$ yield $(0.7 \mathrm{~g})$.

${ }^{1} \mathrm{H} \mathrm{NMR}\left(\mathrm{CDCl}_{3}\right): 7.24(\mathrm{~m}, \mathrm{CH}, 8 \mathrm{H}), 7.06(\mathrm{~m}, \mathrm{CH}, 2 \mathrm{H}), 5.04(\mathrm{~m}, \mathrm{CH}, 2 \mathrm{H}), 2.19,2.16\left(\mathrm{~d}, \mathrm{CH}_{2}, 4 \mathrm{H}\right)$, $1.80\left(\mathrm{~m}, \mathrm{CH}_{2}, 4 \mathrm{H}\right), 1.36\left(\mathrm{~s}, \mathrm{CH}_{3}, 12 \mathrm{H}\right), 1.28\left(\mathrm{~s}, \mathrm{CH}_{3}, 12 \mathrm{H}\right)$.

${ }^{13} \mathrm{C} \mathrm{NMR}\left(\mathrm{CDCl}_{3}\right): 154.2,145.0,128.0,124.1,121.7,70.7,61.2,45.3,32.2,25.5$.

\subsection{Thermal Degradation Behaviour and Tuning of Sulfenamide Structure}

Thermal stability of sulfenamides is affected by the R-groups attached to $S$ (R1) and N (R2, R3). Low basicity and increased number of substitutions of the nitrogen atom increase the stability. Thermal stability decreases, if R1 contains groups capable of anchimeric assistance in cleavage of the S-N bond, whereas electron withdrawing substituents on $\mathrm{R}$ increase the thermal stability [33]. Delocalization of the nitrogen non-bonding electron pair decreases the basicity of amine, and therefore electron withdrawing groups on R2 and R3 decrease the likelihood of $\mathrm{N}$ protonation. Effective delocalization can lead to inversion of the trigonal pyramidal geometry of $\mathrm{N}$ towards planar trigonal. The latter geometry is beneficial also for the stabilization of the nitrogen radical formed during the cleavage of the S-N bond. Heterocyclic aromatics containing nitrogen atoms bonded to carbonyl groups, as in phthalimide, tend to be highly thermally stable. Nitrogen atoms in aromatic heterocyclic structures, as in group V compounds, or bonded to carbonyl groups, as in group VI compounds, tend to have planar geometry. In addition, sterical hindrance can protect the nitrogen. The effect of structure on thermal stability is illustrated in Scheme 2 for a series of SN-compounds.

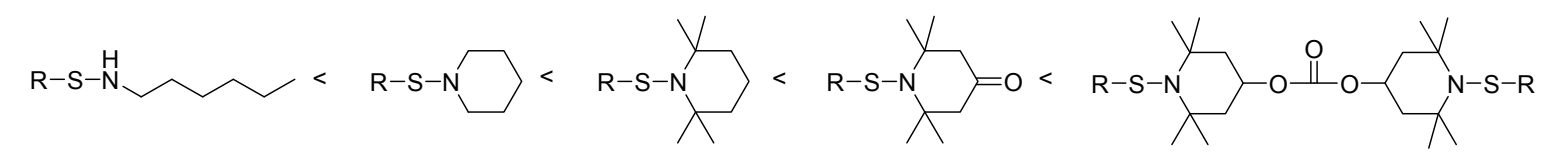

Scheme 2. Substituent effect on thermal stability of sulfenamide compounds. 
Short S-N bond length correlates to the good thermal stability. If the distance between sulfur and nitrogen atoms is less than normal $1.73 \AA$ for a single bond, the bond exhibits some $\pi$-character [34-36]. Thermal decomposition behaviour of sulfenamide accelerators has been extensively studied for rubber vulcanization. To achieve high vulcanization efficiency while simultaneously maintaining long vulcanization delay (scorch time), sulfenamides with calculational S-N bond length less than $1.67 \AA$ and high stability of the dissociated aminyl radicals are particularly suitable [37]. Consequently, the thermal stability is high, but once the SN-bond decomposes, it does not easily recombine.

Thermal weight loss curves for sulfenamides Ic, IIc, IIIa, Vb, VIa and VIb are shown in Figure 3. Suitable decomposition temperature range for flame retardants used in PP formulations has been marked with a grey border line. The sulfenamide should not decompose during PP processing at temperatures up to $230^{\circ} \mathrm{C}$. However, it should be activated in the temperature range of $250-360{ }^{\circ} \mathrm{C}$ when the pyrolysis products of PP (aliphatic saturated and unsaturated hydrocarbons) from the surface are becoming sufficiently vaporized for ignition to take place [38]. In this context, it can be stated that all of the tested sulfenamide compounds exhibited appropriate thermal properties for potentially being suitable flame retardants for PP. Unlike the other sulfenamides, compounds $\mathrm{Vb}$ and VIa had relatively high char residues of $15-20 \mathrm{wt} \%$ at $700{ }^{\circ} \mathrm{C}$, which was related to their structural capability to form polyaromatic condensation products.

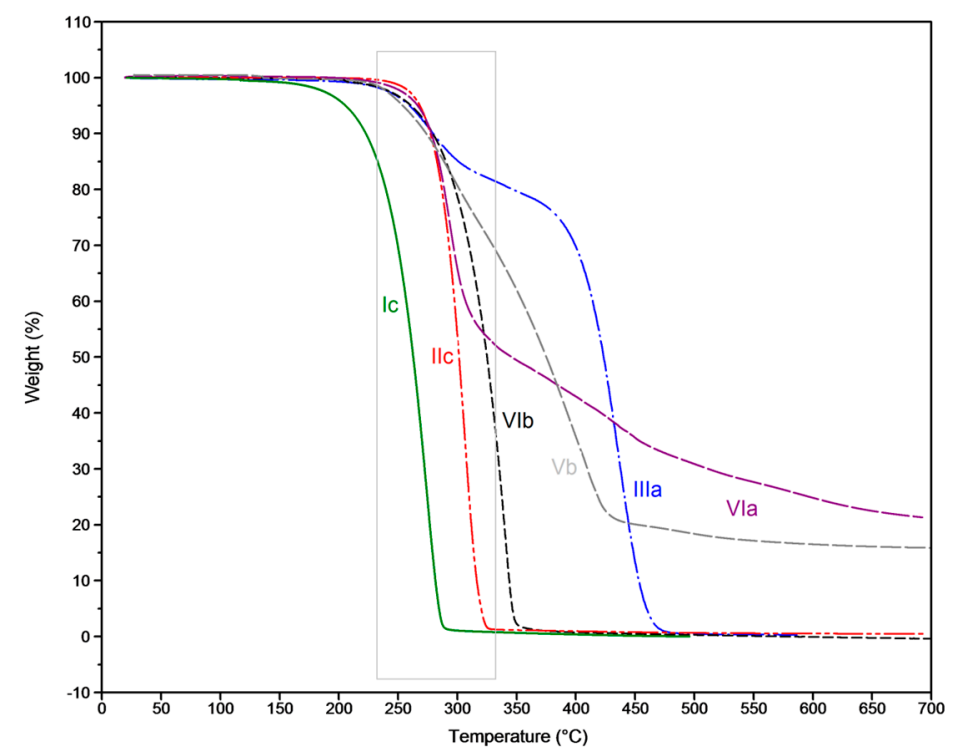

Figure 3. Collected thermogravimetric analysis (TGA) graphs of sulfenamides denoted Ic, IIc, IIIa, $\mathrm{Vb}$, VIa and VIb. The optimal temperature range for flame retardant (FR) decomposition between polypropylene $(\mathrm{PP})$ processing $\left(230{ }^{\circ} \mathrm{C}\right)$ and ignition temperatures $\left(250-360{ }^{\circ} \mathrm{C}\right)$ is marked with a grey border.

\subsection{Flame Retardancy Tests}

All polypropylene, low density polyethylene and polystyrene formulations containing various sulfenamides as flame retardant additives successfully pass the DIN 4102-1 B2 classification. According to the DIN 4102-1 standard, a $20 \mathrm{~mm}$ flame is applied for $15 \mathrm{~s}$, and the average burning time when the flame is removed is recorded. However, in many cases, the sample self-extinguished already before the flame was removed, and only melting was detected after that. Therefore, in Tables 1-3, burning time is given from the application of flame, not from the flame removal. In addition, a $40 \mathrm{~mm}$ flame was used in order to better differentiate between the flame retardant efficacies of different sulfenamide derivatives. DIN 4102-1 B2 classification is comparable with class E in the EN 13501-1 "Fire classification of construction products and building elements". 
The first group of synthesized sulfenamides based on 2,2,6,6-tetramethylpiperidinone, i.e., Ic-Id, with different thioaryl groups exhibited all very similar and short burning times in thin polypropylene films of $200 \mu \mathrm{m}$ (Table 1).

Table 1. Temperature at $5 \%$ mass loss $\left(\mathrm{T}_{5} \%\right.$ ) for pure flame retardant $(\mathrm{FR})$ and flame retardancy results for polypropylene (PP) with a given amount of added FR.

\begin{tabular}{|c|c|c|c|c|c|}
\hline \multirow{2}{*}{$\begin{array}{l}\text { Flame } \\
\text { retardant }\end{array}$} & \multirow{2}{*}{$\begin{array}{l}\text { TGA weight } \\
\text { loss } T_{5 \%}\end{array}$} & \multicolumn{4}{|c|}{ DIN $4102-1$ B2 $^{1}$} \\
\hline & & FR amount (wt \%) & $\begin{array}{l}\text { Average damage } \\
\text { length (mm) }\end{array}$ & $\begin{array}{l}\text { Average burning } \\
\text { time (s) }{ }^{2}\end{array}$ & (Pass/Fail) \\
\hline Reference PP & & 0 & 190 & 39 & Fail \\
\hline Ia & $\mathrm{ND}^{3}$ & 0.5 & 71 & 15 & Pass \\
\hline $\mathrm{Ib}$ & ND & 0.5 & 56 & 8 & Pass \\
\hline Ic & ND & 0.5 & 68 & 9 & Pass \\
\hline Id & ND & 1.0 & 64 & 16 & Pass \\
\hline IIa & 264 & 1.0 & 102 & 12 & Pass \\
\hline $\mathrm{IIb}$ & 248 & 1.0 & 81 & 10 & Pass \\
\hline IIc & 269 & 1.0 & 76 & 11 & Pass \\
\hline IIIa & 254 & 1.0 & 80 & 12 & Pass \\
\hline IIIb & 259 & 1.0 & 83 & 18 & Pass \\
\hline $\mathrm{IVb}$ & 234 & 0.5 & 98 & 23 & Pass \\
\hline Va & 238 & 1.0 & 75 & 12 & Pass \\
\hline $\mathrm{Vb}$ & 254 & 1.0 & 61 & 7 & Pass \\
\hline VIa & 266 & 0.5 & 67 & 14 & Pass \\
\hline $\mathrm{VIb}$ & 265 & 1.0 & 69 & 18 & Pass \\
\hline
\end{tabular}

${ }^{1}$ DIN 4102-1 B2 classification is comparable with class E in the EN 13501-1 "Fire classification of construction products and building elements". ${ }^{2}$ Burning time is calculated from the application of flame. Flame application time $15 \mathrm{~s}$, edge ignition, flame height $40 \mathrm{~mm}$. PP film thickness $200 \mu \mathrm{m} .{ }^{3} \mathrm{ND}=$ not determined. TGA $=$ thermogravimetric analysis.

Additional fire tests were performed using Ic in thick polypropylene plaques of $1 \mathrm{~mm}$ in accordance with DIN 4102-1 standard and films of $300 \mu \mathrm{m}$ based on a UL94 VTM test standard. The results revealed that even polypropylene plaques and films containing $0.5 \mathrm{wt} \%$ of Ic passed the criteria's set forth for DIN 4102-1 B2 (see Table 2) and UL94 VTM-2 classifications, respectively.

Table 2. Flammability results for $1 \mathrm{~mm}$ thick PP plaques with a given amount of added FR.

\begin{tabular}{ccccc}
\hline \multirow{2}{*}{ Flame retardant } & \multicolumn{4}{c}{ DIN 4102-1 B2 } \\
\cline { 2 - 5 } & FR amount (wt \%) & Average damage length (mm) & Average burning time (s) $\mathbf{1}^{\mathbf{1}}$ & Pass/Fail \\
\hline Ic & 1.0 & 43 & 20 & Pass \\
IIb & 1.0 & 43 & 21 & Pass \\
IIc & 1.0 & 52 & 30 & Pass \\
\hline
\end{tabular}

\footnotetext{
${ }^{1}$ Burning time is calculated from the application of flame. Flame application time $15 \mathrm{~s}$, edge ignition, flame height $40 \mathrm{~mm}$.
}

The prepared LDPE samples flame retarded with Ia and IIa passed the DIN 4102-1 B2 test. Both burning time and damage length were, however, somewhat longer than for the corresponding PP thin samples (Table 3).

Table 3. Flammability results for low density polyethylene (LDPE) with a given amount of added FR.

\begin{tabular}{ccccc}
\hline \multirow{2}{*}{ Flame retardant } & \multicolumn{4}{c}{ DIN 4102-1 B2 } \\
\cline { 2 - 5 } & FR amount $\mathbf{( w t} \%)$ & Average damage length $\mathbf{( m m )}$ & Average burning time $\mathbf{( s )} \mathbf{1}^{\mathbf{1}}$ & $\mathbf{~ ( P a s s / F a i l ) ~}^{\text {(P) }}$ \\
\hline Reference LDPE & 0 & 190 & 37 & Fail \\
Ia & 0.5 & 108 & 30 & Pass \\
IIa & 0.5 & 133 & 36 & Pass \\
& 1.0 & 122 & 28 & Pass \\
\hline
\end{tabular}

\footnotetext{
${ }^{1}$ Burning time is calculated from the application of flame. Flame application time $15 \mathrm{~s}$, edge ignition, flame height
} $40 \mathrm{~mm}$. LDPE film thickness $200 \mu \mathrm{m}$. 
The second group of sulfenamides was based on bis(2,2,6,6-tetramethyl piperidinyl) that are less volatile than group I sulfenamides. The samples self-extinguished even before flame removal (Table 1). The recorded damage lengths above $55 \mathrm{~mm}$ were mainly caused by polymer melting. The thermal stabilities were dependent on the linker moiety $\mathrm{X}$ and increased in the following order: $\mathrm{Ilb}<\mathrm{IIa}<\mathrm{IIC}$. The compound IIc was chosen as the most promising candidate in this series due to its excellent flame retardant efficacy, high thermal stability, excellent processing behavior and clarity of the produced polypropylene film.

The third group of sulfenamides consisted of polymeric sulfenamide structures. Tentative structures for the reaction products of Uvinul ${ }^{\circledR} 5050 \mathrm{H}$ and Sabo ${ }^{\circledR}$ stab UV 94 are shown in Figure 4. Similar thermal stabilities and anti-flame properties were recorded for both polymeric compounds IIIa and IIIb (Table 1). The result demonstrates that polymeric sulfenamides are also able to effectively impart flame retardancy to polypropylene films.

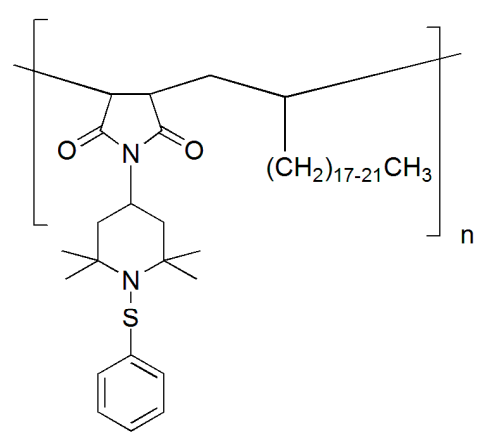

Compound IIIa

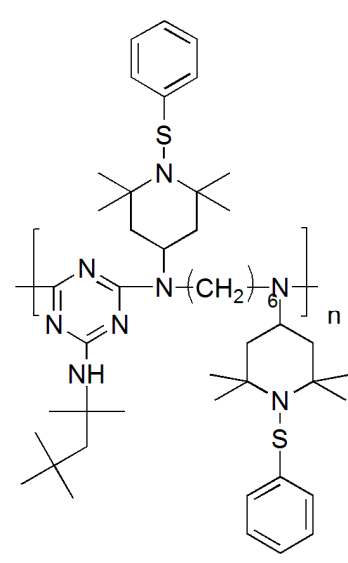

Compound IIIb

Figure 4. Tentative structures for polymeric compounds IIIa and IIIb.

Sulfenamides belonging to group IV contain benzothiazole moieties, and they were commercially available. Traditionally, these types of sulfenamides are used as non-nitrosamine generating accelerators in rubber vulcanization. Compound IVb was thermally more stable than most sulfenamides used in the rubber industry, and was therefore selected to be the more potent candidate as a flame retardant for PP within this family of sulfenamides. Interestingly, this structure passed the DIN 4102 B2 flammability test, but it was not as effective as the 2,2,6,6-tetramethylpiperidine based sulfenamides of group I (Table 1).

One of the most impressive results was obtained when $5 \mathrm{wt} \%$ of sulfenimide IVa was used in $1.6 \mathrm{~mm}$ thick polystyrene sticks (Table 4). Thus, the stringent UL94 V-0 rating was successfully reached. The reference virgin PS burned very vigorously with a high flame. In contrast, polystyrene containing IVa exhibited excellent flame retardant properties with a total burning time of only $4 \mathrm{~s}$ for five sticks.

Table 4. UL $94 \mathrm{~V}$ test results for polystyrene.

\begin{tabular}{ccccc}
\hline \multirow{2}{*}{ Flame retardant } & \multirow{2}{*}{ TGA weight loss T $_{\mathbf{5} \%}$} & \multicolumn{3}{c}{ UL 94 V } \\
\cline { 3 - 5 } & & FR amount (wt \%) & Total burning time (s) $\mathbf{1}^{\mathbf{2}}$ & Rating (V-0/Fail) \\
\hline Reference PS & - & 0 & ND & Fail \\
Iva & 194 & 5 & 4 & V-0 \\
\hline
\end{tabular}

${ }^{1}$ Total burning time for five sticks of $1.6 \mathrm{~mm}$ thickness. UL94 $\mathrm{V}=$ Underwriters laboratories standard test for vertical specimens [27].

The fact that IVa is such an effective FR in polystyrene was attributed to generation of different radicals depicted in Figure 5, which by a cascade of different reactions take part in degradation 
enhancement of polystyrene as earlier described in the literature $[14,39,40]$. When thiyl and amine radicals are generated by thermal cleavage, they can abstract hydrogen from polystyrene backbone, form intermediate reaction products where sulfur species (e.g., polysulfides) are attached to polystyrene and take part in various kind of chain transfer and telomerization reactions. Sulfur catalyzed recombination of flame radicals can also occur.

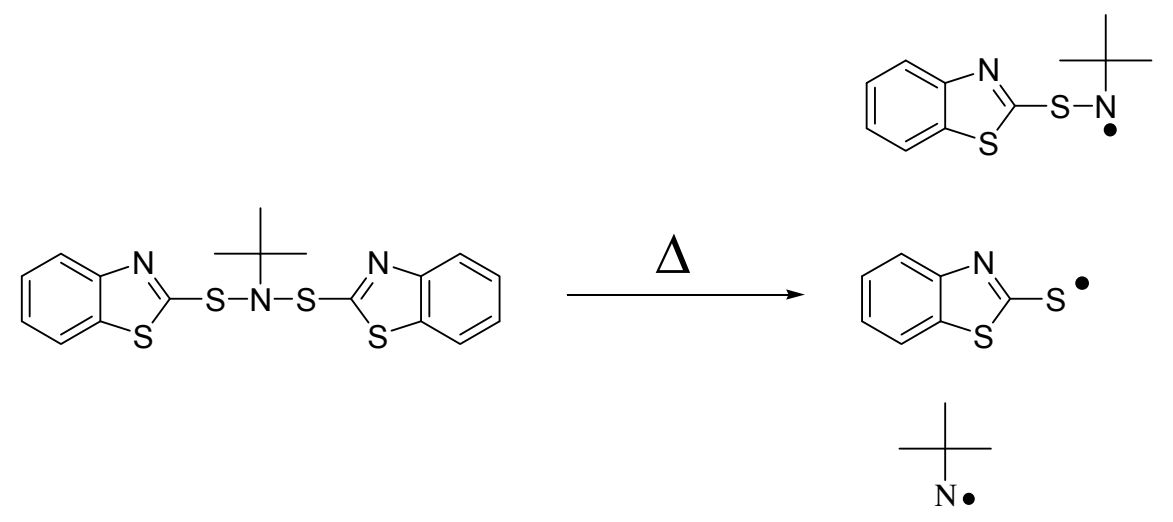

Figure 5. Possible radicals generated by thermal decomposition of IVa.

In order to study amine moieties with a very high charge dissipation capacity, carbazole based sulfenamide derivatives of group $\mathrm{V}$ were synthesized. The thermal stability of compounds $\mathrm{Va}$ and $\mathrm{Vb}$ was expected to be high due to planarity of $\mathrm{N}$. Both compounds exhibited excellent flame retardant performance at a loading of $1 \mathrm{wt} \%$ without any flame dripping. Compound $\mathrm{Vb}$ had slightly higher thermal stability and showed better flame retardancy than compound Va. Both compounds also passed the criteria for UL94 VTM-2.

The sixth group of sulfenamides contained imide and imidazole moieties. In the imide and imidazole derivatives, the $\mathrm{N}$ atom is next to electron withdrawing carbonyl groups. In theory, this type of sulfenamides should have high thermal stabilities and excellent free-radical quenching capabilities. It was found that both VIa and VIb could effectively improve the flame retardancy of polypropylene films.

\section{Conclusions}

We have shown that, when exposed to a small ignition source, various sulfenamide derivatives can help to self-extinquish films of PP, LDPE and PS already at a very low dosage ranging from $0.5-5 \mathrm{wt} \%$. In general, at these very low loadings, various radical generators do not provide sufficient fire protection when the polymers are exposed to more harsh fire scenarios such as in cone calorimeter tests alone, but they can be used to enhance protection given by intumescent or char forming systems, as will be shown in our subsequent paper. However, fire often starts by a small ignition source. If the material around it self-extinguishes, it can effectively prevent fire from spreading. Studies related to their flame retardant mechanism are also under way.

Acknowledgments: Financial support from the Finnish national Center of Excellence for Functional Materials (FUNMAT, 2008-2013) is greatly acknowledged.

Author Contributions: Teija Tirri, Melanie Aubert, Weronika Pawelec and Carl-Eric Wilen conceived and designed the experiments. Teija Tirri and Weronika Pawelec contributed most to the synthesis and analysis of the compounds. Anton Holappa and Teija Tirri did the flame retardant testing. Teija Tirri had the main responsibility for the analysis of the data and writing of the paper. Carl-Eric Wilen and Melanie Aubert supervised the research work.

Conflicts of Interest: The authors declare no conflict of interest. 


\section{References}

1. De Wit, C.A. An Overview of Brominated Flame Retardants in the Environment. Chemosphere 2002, 46, 583-624. [CrossRef]

2. Levchik, S. Phosphorus-Based FRs. In Non-Halogenated Flame Retardant Handbook; Morgan, A.B., Wilkie, C.A., Eds.; John Wiley \& Sons Inc.: Hoboken, NJ, USA, 2014; pp. 17-74.

3. Salmeia, K.A.; Fage, J.; Liang, S.; Gaan, S. An Overview of Mode of Action and Analytical Methods for Evaluation of Gas Phase Activities of Flame Retardants. Polymers 2015, 7, 504-526. [CrossRef]

4. Klatt, M. Nitrogen-Based Flame Retardants. In Non-Halogenated Flame Retardant Handbook; Morgan, A.B., Wilkie, C.A., Eds.; John Wiley \& Sons Inc.: Hoboken, NJ, USA, 2014; pp. 143-168.

5. Schartel, B. Phosphorus-Based Flame Retardancy Mechanisms-Old Hat or a Starting Point for Future Development? Materials 2010, 3, 4710-4745. [CrossRef]

6. Horsey, D.W.; Andrews, S.M.; Davis, L.H.; Dyas, D.D.; Gray, R.L.; Gupta, A.; Hein, B.V.; Puglisi, J.S.; Ravichandran, R.; Shields, P.; et al. Flame Retardant Compositions. WO 1999000450 A1, 7 January 1999.

7. Tirri, T.; Aubert, M.; Pawelec, W.; Wilen, C.; Pfaendner, R.; Hoppe, H.; Roth, M.; Sinkkonen, J. Preparation and Characterization of Bis-[1,3,5]Triazinyl Diazenes and their Utilization as Flame Retardants in Polypropylene Films. J. Appl. Polym. Sci. 2014, 131, 40413/1-40413/9. [CrossRef]

8. Aubert, M.; Tirri, T.; Wilen, C.; Francois-Heude, A.; Pfaendner, R.; Hoppe, H.; Roth, M. Versatile Bis(1-Alkoxy-2,2,6,6-Tetramethylpiperidin-4-Yl)-Diazenes (AZONORs) and Related Structures and their Utilization as Flame Retardants in Polypropylene, Low Density Polyethylene and High-Impact Polystyrene. Polym. Degrad. Stab. 2012, 97, 1438-1446. [CrossRef]

9. Aubert, M.; Wilen, C.; Pfaendner, R.; Kniesel, S.; Hoppe, H.; Roth, M. Bis(1-Propyloxy-2,2,6,6Tetramethylpiperidin-4-Yl)-Diazene-an Innovative Multifunctional Radical Generator Providing Flame Retardancy to Polypropylene Even after Extended Artificial Weathering. Polym. Degrad. Stab. 2011, 96, 328-333. [CrossRef]

10. Aubert, M.; Nicolas, R.C.; Pawelec, W.; Wilen, C.; Roth, M.; Pfaendner, R. AzoalkaneS-Novel Flame Retardants and their Structure-Property Relationship. Polym. Adv. Technol. 2011, 22, 1529-1538. [CrossRef]

11. Pawelec, W.; Aubert, M.; Pfaendner, R.; Hoppe, H.; Wilen, C. Triazene Compounds as a Novel and Effective Class of Flame Retardants for Polypropylene. Polym. Degrad. Stab. 2012, 97, 948-954. [CrossRef]

12. Pawelec, W.; Holappa, A.; Tirri, T.; Aubert, M.; Hoppe, H.; Pfaendner, R.; Wilen, C. Disulfides-Effective Radical Generators for Flame Retardancy of Polypropylene. Polym. Degrad. Stab. 2014, 110, 447-456. [CrossRef]

13. Pfaendner, R.; Metzsch-Zilligen, E.; Stec, M. Use of Organic Oxy Imides as Flame Retardants for Plastics and Flame-Retardant Plastics Composition and Mouldings Produced Therefrom. WO 2014154636A1, 2 October 2014.

14. Wagner, J.; Deglmann, P.; Fuchs, S.; Ciesielski, M.; Fleckenstein, C.A.; Doering, M. A Flame Retardant Synergism of Organic Disulfides and Phosphorous Compounds. Polym. Degrad. Stab. 2016, 129, 63-76. [CrossRef]

15. Rakotomalala, M.; Ciesielski, M.; Zevaco, T.; Doering, M. New Phosphacyclic Molecules and their Application as Flame Retardants for Epoxy Resins. Phosphorus Sulfur Silicon Relat. Elem. 2011, 186, 989-996. [CrossRef]

16. Chen, Y.; Peng, H.; Li, J.; Xia, Z.; Tan, H. A Novel Flame Retardant Containing Phosphorus, Nitrogen, and Sulfur. J. Therm. Anal. Calorim. 2014, 115, 1639-1649. [CrossRef]

17. Wilen, C.E.; Aubert, M.; Tirri, T.; Pawelec, W. Sulfenamides as Flame Retardants. WO 2015067736A1, 14 May 2015.

18. Zincke, T. New Series of Aromatic Sulfur Compounds. Ber. Dtsch. Chem. Ges. 1911, 44, 769-771. [CrossRef]

19. Koval, I.V. Synthesis and Application of Sulfenamides. Russ. Chem. Rev. 1996, 65, 421-440. [CrossRef]

20. Nti-Addae, K.W. Synthesis and Physiochemical Characterization of Sulfenamide Prodrugs of Antimicrobial Oxazolidinones. Ph.D. Thesis, University of Kansas, Lawrence, KS, USA, December 2008.

21. Cohen, M.P.; D'Sidocky, R.M. Rubber Chemicals. In Encyclopedia of Polymer Science and Technology; John Wiley \& Sons Inc.: Hoboken, NJ, USA, 2002.

22. Yoo, J. Synthesis of New Biodegradable Polysulfenamides for Applications in Medicine. Ph.D. Thesis, University of Iowa, Iowa City, IA, USA, 2011. 
23. Yoo, J.; Kuruvilla, D.J.; D’Mello, S.R.; Salem, A.K.; Bowden, N.B. New Class of Biodegradable Polymers Formed from Reactions of an Inorganic Functional Group. Macromolecules 2012, 45, 2292-2300. [CrossRef] [PubMed]

24. Yoo, J.; Kuruvilla, D.J.; Salem, A.K.; Bowden, N.B. New Biodegradable Polymers with Sulfenamide Bonds for Drug Delivery Applications. WO 2012115806A1, 30 August 2012.

25. Eichhorn, J. Synergism of Free Radical Initiators with Self-Extinguishing Additives in Vinyl Aromatic Polymers. J. Appl. Polym. Sci. 1964, 8, 2497-2524. [CrossRef]

26. Eichhorn, J. Self-Extinguishing Resins, especially Polystyrene. FR1391298, 5 March 1391.

27. Underwriters Laboratories. UL 94: Standard for Tests for Flammability of Plastic Materials for Parts in Devices and Appliances; Underwriters Laboratories Inc.: Northbrook, IL, USA, 1998.

28. Craine, L.; Raban, M. The Chemistry of Sulfenamides. Chem. Rev. 1989, 89, 689-712. [CrossRef]

29. Davis, F.A. Adventures in Sulfur-Nitrogen Chemistry. J. Org. Chem. 2006, 71, 8993-9003. [CrossRef] [PubMed]

30. Koval, I.V. Sylfenyl Chlorides in Organic Synthesis. Russ. Chem. Rev. 1995, 64, 731-751. [CrossRef]

31. Koval, I.V. Advances in the Chemistry of Sulphenic Acid Amides. Russ. Chem. Rev. 1990, 59, $396-403$. [CrossRef]

32. Kharasch, N.; Potempa, S.J.; Wehrmeister, H.L. The Sulfenic Acids and their Derivatives. Chem. Rev. 1946, 39, 269-332. [CrossRef] [PubMed]

33. Heimer, N.E.; Field, L. Organic Disulfides and Related Substances. XXIX. Sulfenamides. J. Org. Chem. 1970, 35, 3012-3022. [CrossRef]

34. Sato, S.; Yoshioka, T.; Tamura, C. The Crystal Structures of 2,2,6,6-Tetramethyl-4-oxopiperidine Derivatives. Acta Crystallogr. B 1975, 31, 1385-1392. [CrossRef]

35. Brito, I.; Lopez-Rodriguez, M.; Vargas, D.; Leon, Y. N,N-Dibenzyl-3-nitrobenzenesulfenamide. Acta Crystallogr. A 2006, 62, o914-o916. [CrossRef]

36. Bharatam, P.V.; Kaur, A.; Kaur, D. Electronic Structure of N-Sulfenylimines. J. Phys. Org. Chem. 2003, 16, 183-188. [CrossRef]

37. Ohtsuki, M.; Sato, Y. Rubber Composites with Good rubber/metal Adhesion and Rubber Compositions with Proper Vulcanization Reaction without the Vulcanization Retarder. WO 2010150419 A1, 29 December 2010.

38. Hopkins, D.; Quintiere, J.G. Material Fire Properties and Predictions for Thermoplastics. Fire Saf. J. 1996, 26, 241-268. [CrossRef]

39. Beach, M.W.; Rondan, N.G.; Froese, R.D.; Gerhart, B.B.; Green, J.G.; Stobby, B.G.; Shmakov, A.G.; Shvartsberg, V.M.; Korobeinichev, O.P. Studies of Degradation Enhancement of Polystyrene by Flame Retardant Additives. Polym. Degrad. Stab. 2008, 93, 1664-1673. [CrossRef]

40. To, B.H.; Sikora, D.J. N-t-Butyl Benzothiazole Sulfenimide a New Long-Delay, Slow-Curing Primary Amine Based Accelerator. Nippon Gomu Kyokaishi 1994, 67, 132-141. [CrossRef] 